\title{
ESCRIBIR LEJOS, LEER DE CERCA: SOSNOWSKI, CARTÓGRAFO DEL DISCURSO CRÍTICO LATINOAMERICANO
}

\author{
Sobre Saúl Sosnowski. Cartografía de las letras \\ hispanoamericanas: tejidos de la memoria. Villa María: EDUVIM, \\ 2015. 222 pp.
}

Facundo Gómez. INDEAL - UBA

Desde hace décadas, Saúl Sosnowski ha desarrollado en la academia norteamericana una prolífica labor en el área de los estudios latinoamericanos. Lejos de limitarse al examen crítico de las obras principales de nuestro canon, su trabajo se vuelca tanto hacia la revisión de la crítica literaria producida en el continente, como a la reflexión sobre los procesos culturales vinculados con las dictaduras del Cono Sur y sus consecuencias en los sistemas democráticos que las reemplazaron. Sobre estos ejes transita su libro Cartografía de las letras hispanoamericanas: tejidos de la memoria (2015), publicado por la editorial universitaria argentina EDUVIM en su colección Zona Crítica, que reúne aportes de distintos especialistas en función de reponer el entramado de lecturas e intervenciones que constituye al discurso crítico latinoamericano.

A través de los seis capítulos que componen el libro, Saúl Sosnowski reconstruye parte de su trayectoria, marcada notablemente por los devenires de la historia política más reciente y por su constante actividad en el campo intelectual latinoamericano, en cuyo seno participa como director $y$ 
creador de la revista Hispamérica, docente de la Universidad de Maryland y organizador de relevantes foros de discusión e intercambio cultural. Tal como él mismo lo señala en el prólogo, los espacios y las geografías son elementos centrales en su interpretación de nuestras letras, tensada por la doble afiliación que implica enseñar en Estados Unidos y pensar la narrativa producida al sur del río Bravo sin renunciar a una perspectiva actualizada en lo disciplinar ni a un sostenido compromiso con los desafíos culturales de las nuevas coyunturas. Desde ese lugar de enunciación, Sosnowski propone una cartografía que funciona más bien como bitácora de uno de los más reconocidos exploradores del corpus literario latinoamericano.

El primer capítulo del libro es el más extenso y el que más se adecua al carácter de panorama que propone el título de la obra. Conformado a partir del prólogo a los cuatro volúmenes sobre crítica literaria latinoamericana que el mismo Sosnowski compiló y editó para Biblioteca Ayacucho, el ensayo versa sobre las problemáticas centrales que han debido atravesar los estudios literarios para leer, analizar y organizar la producción continental en la segunda mitad del siglo xx. El punto de partida es la década de 1960, en cuyo seno se desencadena, a partir de la Revolución Cubana, una aceleración histórica que pone a América Latina en el centro de la escena política y cultural. La publicación, en muy pocos años, de una serie de novelas que renuevan las estéticas vigentes hasta entonces se conjuga con el surgimiento de un discurso crítico urgido por entablar una lectura rigurosa de las recientes obras de ficción y comprometido con las proyectos transformadores en ascenso. A medida que indaga los logros y obstáculos de las dos tendencias críticas que se van desarrollando a la par (una, bajo el amparo de la especificidad de las disciplinas y con un marcado sesgo inmanentista; otra, con una motivación política 
que la impulsa a una ambición de miras que excede lo literario, 83), Sosnowski llama la atención sobre el ambiguo sentido del "boom" literario, que por un lado inscribe a la literatura latinoamericana en el más amplio contexto mundial y por otro la somete a una homogeneización labrada a partir de los moldes estéticos de sus novelas señeras. Ya hacia la década de 1970, la centralidad de los grandes nombres cede ante el estallido de nuevas propuestas que operan con géneros, cosmovisiones y lenguajes despreciados por la gran literatura hasta entonces, como el folletín, las letras de boleros y tangos, el mundo del cine y del rock o las estéticas barrocas. Finalmente, el crítico se adentra en los cuestionamientos del canon literario que se rastrean en diversas iniciativas de las décadas de 1980 y 1990, para postular una definición de la literatura latinoamericana que se destaca por su negatividad: "La maravilla americana es el rechazo en sí, el no someterse a lo anticipado ni responder a las demandas de metrópolis con perfiles cada vez más difusos [...]" (59), afirma Sosnowski oportunamente.

Sus afirmaciones contemplan marcadas simpatías y rechazos. La asunción explícita de la crítica literaria como actividad intelectual comprometida con el contexto social en que se inserta y condicionada por la institución en la que se ejerce confronta directamente con las tendencias academicistas que apelan a la asepsia disciplinar y al uso de jergas sofisticadas para vedar el acceso del público no iniciado a nuestro rico y complejo legado crítico (88). Por otro lado, su trabajo de compilación de textos representativos de diversas tendencias de los estudios literarios continentales es concebido como un ejemplo del deber de la crítica: trazar mapas con hitos, fronteras, constelaciones y corrientes que colaboren con una empresa colectiva de conocimiento (115). 
Estas reflexiones se hallan reformuladas en otro capítulo del libro, titulado "Voces y diferencias: un espacio compartido para la letras americanas", en el cual se reitera la concepción de la literatura latinoamericana como una irreductible diferencia con los patrones estéticos hegemónicos, pero esta vez en el marco de la globalización neoliberal, en auge hacia la década de 1990. Sosnowski se pregunta por las posibilidades de la crítica para resistir el impulso homogeneizador que lleva a leer todo desde similares rejillas interpretativas y que, en el caso de ciertos departamentos de la academia estadounidense, se cifra a menudo en la impostura de profesores e investigadores nacidos en tierras latinoamericanas que adoptan los esquemas en boga (e incluso el idioma inglés) como medios para posicionarse en un mercado laboral prestigioso y con múltiples beneficios (153). La tentativa es polémica y deriva en una propuesta concreta: la efectiva integración de América Latina, en desmedro de la arrasadora globalización, basada en: "[...] el incremento de la circulación de libros y publicaciones periódicas en el continente; en la reforma de los planes de educación [...]; en el reconocimiento de tradiciones compartidas más que en políticas de exclusión; en la aceptación informada de la diferencia como legado" (168).

Es inevitable reconocer en la frase y los enunciados anteriores los ecos de proyectos intelectuales de las décadas pasadas. Si bien es imprescindible la recuperación del legado de críticos y escritores que concibieron a América Latina como un espacio de resistencia y a la integración regional como una estrategia suficiente para adquirir autonomía en el mundo capitalista, habría que pensar hasta qué punto estas ideas no fueron puestas en duda por la irreversible crisis de la modernidad y la caída de los grandes relatos. Resulta difícil conciliar un nuevo proyecto latinoamericanista con una noción de identidad todavía vinculada a la lengua, la pertenencia 
territorial, la raza, la etnia o la clase social (169), elementos que el mismo discurso crítico fue revisando en los últimos años, aún sin ceder al acatamiento dócil de los imperativos globalizadores.

La lectura de la obra se completa con cuatro capítulos más que podrían ser agrupados en dos bloques con temáticas diferenciadas. El primero de ellos expresa el sostenido interés del crítico hacia la obra de los dos escritores argentinos centrales en el canon del siglo xx: Jorge Luis Borges y Julio Cortázar, sobre quienes ha dictado diversos seminarios y escrito varios libros. El ensayo dedicado al autor de Ficciones explora los sentidos de la Cábala judía para trazar una analogía con el uso dado al género fantástico en los textos borgeanos. La relación entre los desafíos hermenéuticos del cabalista y del escritor, la desconfianza frente al orden aparencial del mundo presente en la obra de Borges y en los textos sagrados, la experiencia de lo eterno e inasible cifrado tanto en el Aleph como en la Torah son algunas de las operaciones comparativas que ensaya aquí el crítico, en un ejercicio de revisión de lo sostenido en su ya clásico Borges y la Cábala: la búsqueda del Verbo (1976). Algo similar ocurre con Cortázar: Sosnowski analiza la obra crítica del escritor argentino a partir de la lectura de un ensayo que había permanecido inédito hasta mediados de la década de 1990. Según el crítico, en "Teoría del túnel. Notas para una ubicación del surrealismo y el existencialismo", escrito originalmente en 1947, se pueden rastrear las inquietudes filosóficas y estéticas más señeras de una narrativa que por ese entonces se hallaba en pleno proceso de producción de cuentos como "Casa tomada" o "Bestiario". Desde esa instancia inaugural de su reflexión literaria, la obra crítica de Cortázar es examinada en sus diferentes inflexiones, entre las cuales se resaltan sus posiciones sobre la literatura revolucionaria y su involucramiento constante con la lucha por 
los derechos humanos en los países de la región que habían caído bajo regímenes militares (197). Nuevamente, la inclusión del artículo en el libro queda justificada por el arco temporal que se extiende entre este prólogo de un tomo de las obras completas del escritor, publicado en 2006, y el libro que el crítico le dedicó a su obra ficcional en 1973, Julio Cortázar: una buisqueda mítica.

El último bloque de capítulos recupera dos textos de Sosnowski sobre problemáticas relacionadas con los traumas y desgarramientos del tejido social latinoamericano causados por la sistematizada represión militar del último período. De esta manera, el anterior recorrido por el panorama de la crítica literaria continental se entrelaza aquí con la reflexión colectiva de escritores e intelectuales sobre el corolario de las dictaduras. Así, a lo largo de dos capítulos, se problematiza acerca de una extenso abanico de cuestiones, tales como los debates entre quienes se exiliaron y quienes se quedaron; las resistencias de Estados y sociedades a aceptar la catástrofe histórica que se atravesó en conjunto; la dificultad del arte y la literatura en representar lo ominoso; la cancelación de proyectos políticos emancipadores y el vaciamiento del lenguaje; la construcción de sistemas democráticos que nacen débiles y bajo la sombra de los aparatos represivos; el valor renovado de la memoria como herramienta de integración regional, identidad nacional y fortalecimiento de los lazos comunitarios. El crítico rescata de esta manera los diferentes encuentros que él mismo organizó en la Universidad de Maryland durante las décadas de 1980 y 1990, que dieron lugar a imprescindibles libros sobre los efectos de la represión en los países sudamericanos y, a la vez, sobre el potencial de la cultura para operar sobre esa experiencia histórica tan inabordable (204). En cierto sentido, los importantes eventos políticos y culturales ocurridos en Argentina entre el último de estos textos, publicado en 2005, y 
la lectura contemporánea del libro dejan algunas proposiciones y enunciados desactualizados en parte. El reconocimiento de la lucha de las organizaciones por los Derechos Humanos y del terrorismo ejercido durante la dictadura por parte del Estado Nacional, la reanudación de los juicios a los responsables de la represión, la ingente producción narrativa que tematiza la vida bajo el régimen, la revisión historiográfica de múltiples facetas del período e incluso los debates acerca del valor de la memoria, colocan a estos dos capítulos como testimonios de debates y desafíos propios de un momento histórico específico, que siguen enriqueciendo la historia intelectual, pero ya no por el protagonismo de la cultura, sino por su articulación con políticas estatales concretas.

Un hilo conductor aparece en todos y cada uno de los capítulos: el pensamiento y la figura de Jorge Luis Borges, quien atraviesa tanto el mapeo de la crítica latinoamericana, como las reflexiones sobre las dictaduras o el análisis de la obra ensayística de Cortázar. Si el libro se propone como cartografía, las aventuras ficcionales y los apuntes teóricos del escritor argentino ascienden como una brújula irreverente; siempre en movimiento, dinámica y útil para atravesar nuevos territorios, perderse momentáneamente y redescubrir luego los ya conocidos. En su conjunto, la compilación de textos de Sosnowski, entendida por él mismo como "un emprendimiento casi arqueológico" (9), ilustra vivamente los periplos de la crítica latinoamericana moderna, desde su ascenso bajo el entusiasmo revolucionario y militante de la década de 1960, hasta su inserción en los debates por la memoria durante una época plagada de silencios e incertidumbres. 